\title{
Postura religiosa de Mateo Alemán
}

\section{MAKIYAMA Hironobu}

Varios críticos ponen en tela de juicio la sinceridad de la fe cristiana de Mateo Alemán, autor de la novela picaresca: Guzmán de Alfarache. J.A. Van Praag descubre los sarcasmos, blasfemias y burlas contra las tradiciones y prácticas cristianas e incluso encuentra los rasgos característicos de la raza judía en los pasajes del Guzmán. El crítico holandés juzga esta novela así: "por más impregnado que esté de teología y de moral católica (...) no puede considerarse como una obra que defendiera y predicara el catolicismo. No niego que sea la obra de un creyente, pero no de un católico, ni aun de un cristiano"1). También está en la misma línea Américo Castro, que considera la fábula de Júpiter y el Contento como invectiva contra el mundo carente de sentido y contra su Creador, calificando tajantemente al novelista de anticristiano: "Mateo Alemán era el más anticristiano entre los contemporáneos de Cervantes, el cual lo tuvo muy presente al ofrecernos una visión del mundo diametralmente opuesta a la del Guzmán de Alfarache"). Más recientemente Benito Brancaforte considera la conversión de Guzmán como una de las etapas que suelen predecer a las caídas que ocurren al estilo de Ś́filo, y cree significativa la falta de amor cristiano en el tratamiento de Sayavedra en la novela para medir la cristianidad del autor: "La literatura, en verdad, sirvió de medio al autor, aquí como en el resto de la obra, para descargar su odio contra Martí y, a la vez, contra la ética y religión de su sociedad, y contra la humanidad en general"3).

Ahora cabe preguntarse: si estos críticos descubren tantos indicios y tantas pruebas del anticristianismo de Alemán, ¿por qué no podín hacerlo los lectores contemporáneos del novelista, que sentían más vivos y cotidianos los asuntos y expresiones religiosas que los lectores de nuestra época? Entre los primeros lectores de su obra, figuraban los inquisidores, teólogos y eclesiásticos que conocían a fondo las materias de la ortodoxia católica, pero ninguno de ellos acusaba 
a Alemán de herético, ni su obra apareció registrada entre los libros prohibidos por la Inquisición.

Al contrario, la novela recibió la alabanza de los clérigos por su moralidad, estilo, agudeza... Dos frailes encargados de la censura (Fray Diego Dávila para la primera parte, y Fray Antonio Freire para la segunda) admitieron su publicación afirmando ideas ortodoxas de la obra, y el primero dice: "no hallo alguna cosa que sea contra la Fe Católica" (p.85) ${ }^{4}$. Fray Custodio Lope participó con dos poemas en la segunda parte, que elogiaban el aspecto moral de la novela. Un agustino "tan discreto como docto" de la Universidad de Salamanca declaró en el acto público que no había "salido a luz libro profano de mayor provecho y gusto hasta entonces, que la primera parte deste libro" (p.471), según testimonia Luis de Valdés ${ }^{5}$. El jesuita Baltasar Gracían tampoco escatimaba los elogios hacia el autor: "Aunque de sujeto humilde, Mateo Alemán (...) fue tan superior en el artificio y estilo, que abarcó en si la invención griega, la elocuencia italiana, la erudición francesa, y la agudeza española". Y cita diversos cuentos alegóricos sacados de la novela como ejemplos de agudezas, uno de los cuales es el cuento alegórico de Júpiter y el Contento en cuestión ${ }^{6}$. Ahora bien, estas reacciones de los clérigos ante la obra de Alemán, ¿no servirán de buena prueba para afirmar las ideas ortodoxas del Guzmán y su autor?

Si consideramos la postura religiosa de Alemán por otras actividades, no olvidemos que es autor de una obra hagiográfica: San Antonio de Padua, escrita en el tiempo intermedio entre la primera y la segunda parte del Guzmán ${ }^{7}$. La crítica se da cuenta de la semejanza estructural y estilística en ambas obras. Se utilizan recursos comunes: enumeraciones, interrogaciones, exclamaciones, sentencias, antítesis, etc. ${ }^{8}$. Por otra parte, los sermones que predica Guzmán con alguna timidez se desarrolla plenamente en esta obra que trata de la vida de un gran predicador: San Antonio de Padua. La portada de la tercera edición valenciana ya lo anuncia: "va muy lleno de doctos y curiosos predicables, para diferentes propositos", y al final del libro se acompaña una "tabla de materias comunes para discursos predicables".

En esta obra se encuentran referencias someras, pero interesantes, que pueden señalar su preocupación por la defensa del catolicismo contra el movimiento herético. Alemán se refiere a la filtración temerosa de las ideas heréticas utilizando 
la doctrina del cuerpo místico para señalar la unidad católica:

Precissa obligacion tenemos de pedir a Dios (...) la vnion, paz y concordia de los Principes Christianos braço y defensa deste cuerpo la Iglesia nuestra Madre, cuya cabeça es Christo Redenptor nuestro; para que vnanimes la defiendan de perseguidores della, y de algunos lobos, que con piel de oueja se maten dentro de la manada de los Catolicos, como lo auemos visto en estos tiempos (f.140r) ${ }^{9)}$.

En la misma obra, al hablar largamente de los demonios y los endemoniados, nuestro escritor presenta la lista de los herejes endemoniados de tiempos antiguos y modernos. Mahoma, Simón Mago, Basílides, Montano, Eutiques, etc. fueron herejes de siglos pasados, y lo fueron también los reformistas desde el punto de vista católico. Se revistieron de demonios Lutero, Karlstadt, Ecolampadio, Bucero, Osiander, Zwingli, John Knox, los anabaptistas, etc. Estos herejes, siguiendo la enseñanza del diablo cayeron en el error y en el pecado. Alemán relata el caso de Zwingli, que se adhería a la herejía por seguir la instrucción del demonio: "Zuinglio dize de si mismo, que su herejía se la enseño vn espiritu, ni sabia si era blanco, si negro" (f.287v). Los anabaptistas cayeron en herejía por haber tomado una bebida, con la cual quedaron endemoniados. Aleman pide castigo para ellos por su pecado: "son herejes, y pecan; y como tales deuen ser castigados" (f.288r).

Pero la persona que mereció mención especial era, naturalmente, Martín Lutero como cabeza de los disidentes. Lutero también recibió la doctrina herética del diablo, que llevaba consigo en sus hombros:

Lutero dize de si mismo, que vino a el vn Diablo, y lo saluda muy cortesmente, y le enseño muchos argumentos, hablandole con boz terrible, y espantosa. Estos tales acontece traer Demonios encima de si, que algunas vezes han sido vistos, como se refiere de Maximiliano primero Emperador, que viendo a Lutero, que dio bozes, diziendo que quitassen aquel hombre de su presencia, porque le via traer sobre sus ombros vn Diablo (f.287v).

Cuando murí Lutero, todos los demonios de la comarca le tributaron homenaje asistiendo a las honras fúnebres "por mandado de su Principe, para que se hallassen juntos al entierro de su nueuo profeta Lutero" (f.288v).

Además en la Ortografía Castellana se encuentra una pequeña referencia al 
calvinismo cuando Alemán ataca a los que hacen una ley ortográfica confundiendo las consonantes y vocales: "Dejáronse pasar los absurdos, i dellos hizieron lei, aunque dijera mejor (cada cosa en su tanto) una seta como la de Calvino" (p.76) ${ }^{10}$.

Ahora vemos el vasto conocimiento de Alemán sobre los temas teológicos y religiosos que se exponen en la novela a través de las digresiones y las actuaciones de los personajes ${ }^{11}$. El nacimiento de nuestro protagonista se reviste del sentido simbólico del pecado original. Su escenario, el pago de San Juan de Alfarache, mereció la única descripción lírica e idealista de la novela al ser calificado de paraíso: "Que con razón, si en la tierra se puede dar conocido paraíso se debe a este sitio el nombre dél" (p.129). Con toda hermosura celestial, este paraíso, como el de la Biblia, encubría la tentación y engaño que conducían a la concepción de nuestro pícaro. El tema del pecado original se reitera a lo largo de la novela atribuyendo el origen de todos los vicios del hombre a la prevaricación de los primeros padres: "Porque como después de la caída de nuestros primeros padres, con aquella levadura se acebó toda la masa corrumpida de los vicios, vino en tal ruina la fábrica deste reloj humano" (p.824).

En efecto, los personajes que aparecen en la novela, con pocas excepciones, pecan de viciosos: unos son ladrones, otros mentirosos, otros lujuriosos, etc. Así Guzmán excusa sus comportamientos por la universalidad de la maldad del hombre: "Todos jugaban y juraban, todos robaban y sisaban: hice lo que los otros" (p.297). La visión pesimista del mundo incambiable se atribuye a la maldad del hombre, que ha cundido a partir de la familia de Adán, a la que se sobrepone la imagen de la familia del protagonista:

Este camino corre el mundo. No comienza de nuevo (...). No tiene medio ni remedio. Así lo hallamos, así lo dejaremos. No se espere mejor tiempo ni se piense que lo fue pasado. Todo ha sido, es y será una misma cosa. El primer padre fue alevoso; la primera madre, mentirosa; el primer hijo, ladrón y fratricida. ¿Qué hay ahora que no hubo, o qué se sepera de lo por venir (p.355).

A pesar de la inclinación hacia la maldad que procede del pecado original, el hombre no debe echarle a Dios la culpa de su mala conducta, puesto que Dios concede el libre albedrío, que es lo esencial del hombre según relata Apolo a Júpiter en un cuento alegorico: "si de lo quitas, no serán hombres" (p.186). Con el 
libre albedrío el hombre tiene que guiar su conducta haciéndose responsable de ella. Así Guzmán reflexiona sobre sus actitudes culpándose a sí mismo de sus vicios:

Libre albedrío te dieron con que te gobernases. La estrella no te fuerza ni todo el cielo junto con cuantas tiene te puede forzar; tú te fuerzas a dejar lo bueno y te esfuerzas en lo malo, siguiendo tus deshonestidades, de donde resultan tus calamidades (p.437).

El hombre es libre de aceptar o rechazar la gracia divina debido al libre albedrío, y por ello, la justificación no se alcanza sólo a través de la fe, sino es necesario demostrar su aceptación con sus obras. En varias ocasiones Guzmán amonesta a sus lectores para que pasen la vida ejemplar ejerciendo obras de devoción, cumpliendo con los sacramentos, etc.: "Como te inclinas a lo dañoso y malo, ¿por qué no imitas al bueno y virtuoso, que ayuna, confiesa, comulga, hace penitencia, acto de sanidad y buena vida?" (p.387).

Por otra parte, la Providencia de Dios, "por cuya poderosa mano y divina voluntad se rige cielo y tierra" (p.183), ayuda y proporciona todo lo que necesita la persona que busca la salvación, ya que "Él sabe bien dar a cada uno aquello de que tiene necesidad de salvarse" (p.273). Nunca falta la gracia de Dios a los que desean salvarse; despierta incluso a los pecadores de sus vicios cuando empiezan a reflexionar sobre sus errores pasados: "quien se quisiere ayudar a salirde cenegal, nunca le faltarán buenas inspiraciones del cielo, que favoreciéndolos actos de virtud los esfuerza, con que, conocido el error pasado, emienden lo presente y lleguen a la perfeción en lo venidedro" (p.671). Así ocurre a Guzmán, que está sumergido en el abismo de la miseria, en el puesto ínfimo de la galera; la inspiración divina le despierta de la vida pasada para convertirse espiritualmente y encaminarse hacia la salvación del alma.

Ahora bien, Alice H. Bushee nos informa sobre el conocimiento bíblico de Alemán; se encuentran referencias a la Biblia, treinta y cinco veces, por lo menos,en el Guzmán, unas nueve en la Ortografía, y naturalmente mucho más en las obras que tratan de las vidas de dos clérigos: en el San Antonio, más de ciento cuarenta veces en trescientos nueve folios, y no menos de treinta en doce folios de la Oración fúnebre de Fray Garcia Guerra ${ }^{12}$.

Fuera de las actividades literarias, Alemán nos deja algunos testimonios que 
señalan la confianza que en él tenía $\mathrm{n}$ los clérigos y la gente cercana a la Iglesia. Nuestro novelista pertenecía a la Hermandad de los Nazarenos de Sevilla, siendo elegido su Hermano Mayor en 1574. Los cofrades le depositaron tanta confianza que le pidieron la redacción de las reglas de la cofradía y después le encargaron los negocios de la compra de una capilla para la misma ${ }^{13)}$. En la tierra mexicana, Alemán se acogí a la protección del arzobispo Fray García Guerra, a quien hubo de conocer durante el viaje transatlántico, y presenció de cerca la última etapa de la vida del prelado. Cuando fallecí́ el arzobispo-virrey, el escritor expresó su pésame dedicándole un libro: Sucesos de don FrayGarcía Guerra seguido de la Oración fúnebre en 1613.

Teniendo en cuenta estas actividades literarias y no literarias de Alemán en que no podemos encontrar ningún rasgo anticristiano ni judaico, no podemos dudar de la sinceridad de la fe católica de nuestro escritor.

\section{Notas}

1) 1954, "Sobre el sentido del Guzmán de Alfarache", Estudios dedicados a Menéndez Pidal, V, Madrid, CSIC. p.286. A. A. Parker refuta estas opiniones de Van Praag atribuyendo sus equivocaciones a la falta de familiaridad con las tradiciones católicas, el desconocimiento de la expresión figurada del español, la dislocación de las frases del contexto y la no distinción entre la voz del narrador y la del autor. Cf. 1971, Los picaros en la literatura, Madrid, Gredos, pp.71 y 200-204. Robert Ricard también señala que el dogma de la Trinidad que el crítico holandés aduce como una de las pruebas heterodoxas de Alemán, era utilizado, más bien, como expresión antijudaica entre los escritores de su época (1970, "Mateo Alemán y el dogma de Trinidad", Homenaje a Elías Serra Rafols, La Laguna, Universidad de La Laguna, pp.209-14).

2) 1971, "Cómo veo ahora el Quijote. Estudio preliminar" a Don Quijote, Madrid, Magisterio Español, pp.43-44. Para la crítica de esta opinión, cf. Eugenio Asensio, 1976, La España imaginada de Américo Castro, Barcelona, El Albir, pp.163-67).

3) 1979, "Introducción" a su edición del Guzmán , Madrid, Cátedra, I, p.64. El mismo dice en otra obra: "Ante este episodio (el enloquecimiento y consiguiente suicidio de Sayavedra), en que Alemán y Guzmán están claramente identificados, resulta grosero hablar del cristianismo 'sincero' de Alemán" (1980, Guzmán de Alfarache: iconversión o proceso de degradacion?, Madison, The Hispanic Seminary of Medieval Studies, pp.11213).

4) Para las citas del Guzmán de Alfarache, utilizamos la edición de Francisco Rico, 1983, 
Barcelona, Planeta.

5) Edmond Cros supone la identidad de dicho agustino con el catedrático de teología Domingo Bañez, e incluso piensa en la posibilidad del contacto personal entre el escritor y el teólogo en la Universidad de Alcalá en que ambos coincidieron uno como estudiante y otro como profesor (1971, Mateo Alemán: Introducción a su vida y a su obra, Salamanca, Anaya, p.143). Para la controversia Bañez-Molina sobre la gracia y la predestinación, que estaba de moda a finales del XVI, y la tendencia bañeciana en el Guzmón, cf. Francisco Rico, "Introducción" a su edición del Guzmón, pp.41-43, nota 49.

6) 1967, "Agudeza y arte de ingenio", Obras completas, ed. Arturo del Hoyo, Madrid, Aguilar, pp.479 y 477 respctivamente.

7) B. Brancaforte piensa que Alemán escribió el San Antonio para camuflar su fe verdadera. Según su opinión, la obra "parece escrita para 'desmentir los espías", opinión que no compartimos (Guzmán de Alfarache, ¿conversión o proceso de degradacion? p.200, nota 12).

8) Cf. Venanzio Todesco, 1937-38, "La forma espressiva di Mateo Alemán e il carattere predominante dell' opera sua", Atti Memorie della R. Accademia di Scienza, Lettere ed Arti in Padova, anno 339, 16, nuova serie 54, pp.89-109.

9) Para las citas del San Antonio de Padua, utilizamos la tercera edición, 1607, Valencia, Pedro Patricio Mey.

10) Para la cita de esta obra, utilizamos la edición de José Rojas Garcidueñas, 1950, México, El Colegio de México.

11) Sobre estos temas, cf. Enrique Moreno Báez, 1948, Lección y sentido del Guzmán de Alfarache , Madrid, CSIC, pp.52-79.

12) 1911, "The Sucesos of Mateo Alemán", Revue Hispanique, 25, pp.566-67.

13) Cf. Guzmán Álvarez, 1953, Mateo Alemón, Buenos Aires, Espasa Calpe Argentina, p.53.

\section{Bibliografia}

Alemán, Mateo, 1979, Guzmán de Alfarache, ed. Benito Brancaforte, Madrid,Cátedra, 2 Vols.

— , 1983, Guzmón de Alfarache, ed. Francisco Rico, Barcelona, Planeta.

— , 1950, Ortografía castellana ed. José Rojas Garcidueñas, México, El Colegio de México.

- 1607, San Antonio de Padua, Valencia, Pedro Patricio Mey.

Álvarez, Guzmán, 1953, Mateo Alemón , Buenos Aires, Espasa Calpe Argentina.

Asensio, Eugenio, 1976, La España imaginada de Américo Castro, Barcelona, El Albir.

Brancaforte, Benito, 1980, Guzmán de Alfarache: ¿concersion o proceso de degradación?, Madison, The Hispanic Seminary of Medieval Studies. 
Bushee, Alice H., 1911, "The Sucesos of Mateo Alemán”, Revue Hispanique, 25, pp.359-457.

Castro, Américo, 1971, "Cómo veo ahora el Quijote. Estudio preliminar" a Don Quijote, Madrid, Magisterio Español.

Cros, Edmond, 1971, Mateo Alemán: Introducción a su vida y a su obra, Salamanca, Anaya. Gracián, Baltasar, 1967, “Agudeza y arte de ingfenio”, Obras completas , ed. Arturo del Hoyo, Madrid, Aguilar.

Moreno Báez, Enrique, 1948, Lección y sentido del Guzmán de Alfarache, Madrid, CSIC.

Parker, A. A., 1971, Los pícaros en la literatura, Madrid, Gredos.

Ricard, Robert, 1970, "Mateo Alemán y el dogma de la trinidad", Homenaje a Elías Serra Rafols, La Laguna, Universidad de La Laguna, pp.209-14.

Todesco, Venanzio, 1937-38, "La forma espressiva di Mateo Alemán e il carattere predominate dell'opera sua", Atti Memorie della R. Accademia di Scienza, Lettere ed Arte in Padova, anno 339, 16, nuova serie 54, pp.89-109.

Van Praag, J. A., 1954, "Sobre el sentido del Guzmán de Alfarache" Estudios dedicados a Menéndez Pidal, V, Madrid, CSIC, pp.283-306. 
$\langle$ Resumen〉

\section{Postura religiosa de Mateo Alemán.}

\section{MAKIYAMA Hironobu}

Varios críticos ponen en tela de juicio la sinceridad de la fe cristiana de Mateo Alemán. Sin embargo, los lecores de su época, incluyendo a los teólogos y eclesiásticos que conocián a fondo las materias de la ortodoxia católica, no señalaban el anticristianismo de Alemán. Más bien, la obra recibió la alabanza de los clérigos por su moralidad, estilo, agudeza, etc.

Por otra parte, no olvidemos que Alemán era autor de una obra hagiográfica: San Antonio de Padua. En esta obra, nos deja unas frases que señalaban su preocupación por la unidad católica. Y consideraba endemoniados a los herejes de tiempos entiguos y modernos. Desde el punto de vista católico, los reformistas fueron herejes también y recibieron los ataques de Alemán Zwingli, Martín Lutero, etc.

Alemán demuestra el vasto conocimiento sobre los temas teológicos y religiosos como el pecado original, el libre albedrío, la justificación, la providencia divina, la gracia, la salvación, etc. que se expone a través de las digresiones y las actuaciones de los personajes de la novela.

Además, Alemán nos deja los testimonios que señalaban la confianza que recibió por parte de los clérigos y la gente cercana a la Iglesia. Fue el Hermano Mayor de la Hermandad de los Nazarenos de Sevilla. En México, se acogió a la protección del arzobispo-virrey Fray García Guerra.

Teniendo en cuenta estas actividades literarias y no literarias del novelista, no podemos dudar la sinceridad de la fe católica de Mateo Alemán. 